\title{
ACRL in Washington, D.C. ACRL programs at the ALA Annual Conference
}

A

LA's 126th Annual Conference was held June 21-27, 2007, in Washington, D.C. Approximately 28,635 librarians, library support staff, exhibitors, writers, educators, publishers, and special guests attended the conference. Ed. note: Thanks to the ACRL members who summarized programs to make this report possible.

\section{Tell me something good, and no surprises, please}

A lively and knowledgeable panel of chief academic officers (CAOs) candidly informed and frequently delighted the audience gathered for the ACRL President's Program "The Art of Persuasion: Strategies for Effective Communication with Chief Academic Officers." Moderator James Honan (senior lecturer, Graduate School

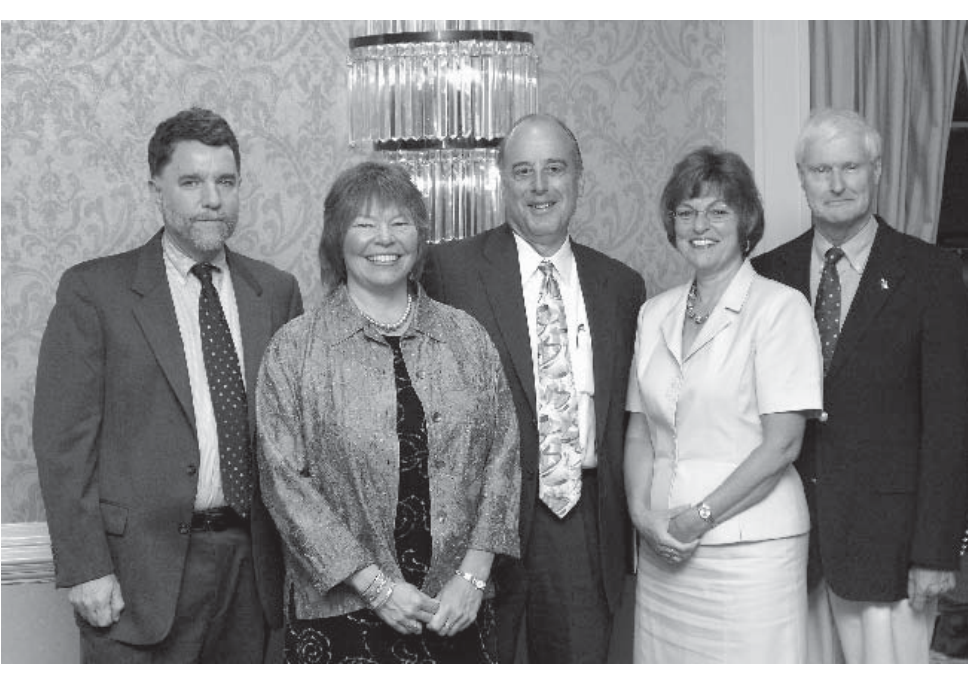

The 2007 President's Program speakers (left to right): Moderator James P. Honan, Harvard University; 2006-07 ACRL President Pamela Snelson; Panelists: William W. Destler, University of Maryland; Elise Bickford Jorgens, College of Charleston; and Dominic Latorraca, County College of Morris. affairs, College of Charleston), and Dominic Latorraca (vice president of academic affairs, County College of Morris) in discussion of the "wildly successful library," communication dos and don'ts for librarians, academic planning and funding, and changing roles among librarians and information technologists.

The panelists shared visions of a wildly successful library as being lively and supportive of the social and self-directed aspects of learning, and featuring a knowledgeable and engaging staff ready to guide users to the best possible resources. When communicating of Education,

Harvard University) engaged panelists William Destler (recent senior vice president for academic affairs and provost, University of Maryland, and now president, Rochester Institute of Technology), Elise Jorgens (provost and senior vice president for academic with a $\mathrm{CAO}$, panelists recommended librarians be prepared to share: 1 . What is working for the librarynot just what is failing or lacking; 2. How the library has solved and can help solve problems and ease transitionsLatorraca recommended starting a conversation with "Hi-I just solved this problem for you ..."; 3. Who the library's allies are and with whom librarians have partnered and collaborated. A strong recommendation from Jorgens- "No surprises, please"—elicited nervous laughter from the audience and audible 
sighs from the panelists. Her recommendation was to never go around the CAO to a higher officer-certainly not the institution's president-with a request or complaint without at some time informing the CAO of the exchange. The same information exchange should also occur if one is contacted directly by a higher-level officer.

Regarding funding requests, it is always good to have allies on campus available to speak on the library's behalf, and to provide information to the CAO detailing how the library has already worked to accommodate budgetary changes, e.g., through consortia purchasing, etc. The panelists concurred that librarians need to be as involved in technology planning and management as possible, but that this involvement-and that of all personnel with technology responsibility-needs to be as clearly defined as possible. Destler drew hearty applause with his comment "The chief information officer's job is to support the library, not the other way around," which concluded the discussion.

A dozen audience members asked wideranging questions during an animated question-and-answer period, and the panelists continued to provide frank and useful advice. As the program drew to a close, a half dozen or more questioners remained, an indication of how much the audience appreciated having direct access to this generous group of CAOs._Lisa Stillwell, Franklin \& Marshall College, lisa.stillwell@fandm.edu

\section{The experiences of mentors and mentees}

The purpose of the ACRL Dr. E. J. Josey Spectrum Scholar Mentor Program is to increase diversity in college and university libraries by encouraging Spectrum Scholars to consider careers in academic librarianship. This is done by pairing them in a relatively structured formal relationship with experienced and successful academic librarians who have agreed to serve as mentors. Theresa Byrd (chair of the committee) opened the session with a brief overview of the work of the committee in developing the program and establishing the policies and procedures for identifying, orienting, and matching volunteer mentors with Spectrum Scholars.

Three teams of mentor/mentees described their experiences under the program. The teams were: 1) Aline Soules (librarian/full professor, California State University-East Bay) and Candice Anne Wing-Yee Mack (MLIS candidate, University of California-Los Angeles [UCLA]), 2) Robert B. Ridinger (chair, electronic information resources, Northern Illinois University) and Joel B. Thornton (intern, University of Texas, Southwestern Medical Center), and 3) Carolyn Henderson Allen (dean of libraries, University of Arkansas) and Brenda Marisol Linares (MLS student, UCLA). Issues addressed included genders of mentors/mentees, ethnicity, geography, communication, networking, career advice, and technology. All of the mentees reported gaining key information about the profession and how to advance. All of the mentors reported learning to view the profession from different perspectives and to be more understanding of how young professionals, especially from underrepresented groups, see things. All of the mentors were optimistic about the next generation of academic librarians. Mentors and mentees all agreed that participation in the program had been a beneficial experience. All of the mentees said that they felt an obligation to pass on their experience and to serve as mentors to those who follow them.

The committee is still looking for experienced academic librarians to serve as E. J. Josey Spectrum Scholar Mentors. Check the ACRL Web site for contact information. -Stanton F. Biddle, Baruch College, City University of New York, e-mail: stanton_ biddle@baruch.cuny.edu

\section{Gaming, information literacy, and the college student}

A standing-room only audience of approximately 350 responded enthusiastically to the thought-provoking presentations on gaming by James Paul Gee (Tashia Morgridge professor of reading, University of Wisconsin-Madison) and George M. Needham (vice president, 
member services, OCLC). This Community and Junior College Libraries Section (CJCLS) program was moderated by Rebecca Schreiner.

James Paul Gee said that with traditional literacy, what predicts success in the first grade is literacy at home. What predicts success in the fourth grade and beyond is the mastery of academic language. Learning comes from situated meaning coming from play, rather than textbook reading. When the gamer is engaged in the game, the manual becomes meaningful. The learning principles at work in gaming include:

- Games are designed to lower the consequences of failure so that the player takes risks and explores and learns from failure.

- Performance before competence.

- Players are high on the agency tree, must make choices and act.

- Problems are well ordered in a rich environment with good guidance and fruitful leads.

- Cycles of challenge, consolidation, and new challenge (expertise).

- Games stay within, but at the outer edge of the player's "regime of competence" to keep players pleasantly frustrated.

- Games encourage players to think about systems and relationships, not just isolated events, facts and skills, to analyze the long- term ramifications.

- Games give verbal information "just in time"- —when a player needs and can use it —or "on demand" when the player asks for it.

- Games situate (show) the meanings of words and symbols and show how they vary across different actions, images, and dialogues. They don't just offer words for words (definitions).

- In games, learning is embodied and affective (emotion tied to learning); if it matters, people learn.

- Games recruit smart tools, distributed knowledge, and cross-functional teams just like modern high-tech workplaces.

- Games offer players strong identities. Players learn to view the virtual world through the eyes and values of a distinctive identity or one they themselves have built from the ground up.
- Games encourage a distinctive view of intelligence: encourage players to explore thoroughly before moving on; to think laterally, not just linearly; and to use such exploration and lateral thinking to rethink one's goals from time to time.

- Gamers develop empathy for a complex system. Simulation inside the game mimics scientific simulations.

- In a gaming environment players not only use and assess information, but also modify it.

George Needham said that OCLC's environmental scan three-and-a-half years ago focused on three trends: self-service, disaggregation, and collaboration. It used gamers as an example.

Today's students are digital natives who have never known a world that's not digital. Digital immigrants have learned it to varying degrees, but retain a "digital accent." In contrast to digital immigrants, digital natives are characterized by "twitch speed" rather than conventional speed, parallel processing rather than linear processing, random access rather than linear thinking, payoff rather than process, fantasy rather than reality, and technology as friend rather than uneasy partner.

Quoting Steven Abram (Sirsi/Dynix) and Judy Luther, Needham described those "born with the chip" as format agnostic, nomadic, multitasking, experiential, collaborative, integrated, principled, adaptive, and direct.

John Beck describes the gamer's view of life: heroes of their own games, performance matters, encourage people to take the lead. The world is a logical, human-friendly place. Games are basically fair. Events may be random, but not unpredictable. Life should be fun. Work should not be punishment. Games have many potential paths to "victory" and the cost of failure is low.

Gaming suggests rethinking how libraries deliver services: multiple paths, many formats and platforms, consider the nonprint learner, the librarian as "information priest" is as dead as Elvis, and what can the user contribute.

Libraries should rethink where libraries serve: physical layouts of libraries; online ser- 
vices are journeys and markers, not destinations; $24 / 7 / 365$ is barely enough.

Needham suggested ways libraries could apply principles learned from gaming: play an online game; offer services on instant messaging; use text messaging; throw a LAN party; bring digital natives into the planning process; respect nonprint learning.

Needham concluded by exhorting that libraries not waste their existence in waiting, but must build as if the sand were stone.-Ann Coder, Brookhaven College Library, Dallas County Community College District,axc2610@dcccd.edu

\section{Embracing change}

More than 550 people attended the College Libraries Section (CLS) program entitled, "Embracing Change: How to Energize and Engage Library Staff."

The keynote speaker was ACRL's Content Strategist Kathryn J. Deiss. Deiss used a series of images from nature to talk about change. She offered a list of suggestions to help deal with change. These included: "change your perspective frequently," "encourage divergent opinions and ideas," and "create new forms and structures in response to observed changes in the patterns around you." Deiss's presentation provided a theoretical background for the practical presentations that followed.

The three presentations that followed were chosen from 15 submissions via a blind peer-reviewed process.

Tara Lynn Fulton was hired as dean of library and information services at Lock Haven University in 2000. When she interviewed she was told that the institution was looking for a dean who would initiate change. She met with the staff to make sure that they were on board before accepting the position. Upon her arrival, she made or initiated the following changes: remodeled the first floor of the building, moved from closed to open periodical stacks, and created teams within the library (Web team, public relations team). Before her arrival, library staff had operated 
allowed people to dress down because of the grime, encouraged group walks, and even hired a yoga teacher for the staff. Finally, Campbell hired an outside consultant to come give a two-day workshop on change. These considerations helped smooth the transition and made for a happier library staff.

This program will be Webcast on November 15, 2007, at 3 p.m. (EST); watch the CLS electronic list for more details. - Ruth S. Connell, Valparaiso University, ruth. connell@valpo.edu

\section{Can blogs be trusted?}

Jason Zengerle, senior editor for the New Republic and contributor to its group blog "The Plank," offered his insights into the world of political blogging to a full house. Liberal blogs were used in the 2000 election to galvanize a movement to broaden the political discussion beyond the beltway. Howard Dean's use of the Internet as a messaging and fundraising tool has inspired countless candidates since then. Zengerle discussed differences between the NewRepublic and bloggers, such as the run-up to the Iraq War. He said that the NewRepublic had been wrong to support the war and said that their attacks on opponents had been "shameful." In 2005, the NewRepublic realized that the news cycle was shortening and that it needed to supplement its weekly coverage of events. "The Plank" was born. This format allowed them to address issues that might not generate a full article in the magazine and cover other blogs.

Zengerle pointed out that some blogs were beginning to break news stories and keep them alive until the mainstream media discovered them. He cited "Talking Points Memo" as a source of more traditional news reporting that had incorporated significant stories, such as the current investigation of the dismissals of several U.S. attorneys.

Zengerle commented that the conservative political movement had been applying pressure to the mainstream media for several years. Reporters and editors have changed the emphasis of their stories to accommodate this pressure. The development of liberal blogs is now applying pressure from the opposite side of the spectrum, so Zengerle said he's now getting attacked from both sides. He feels that this will lead to better balance in reporting in the future.

Zengerle concluded by stating that he thought of blogs as early warning systems that foreshadow the development of upcoming trends, such as the Ned Lamont senate campaign in Connecticut or the Tommy Thompson presidential run. Most political blogs are written to advocate a position and are subject to all the normal biases found in political campaigns and should be evaluated with care.-Catherine Doyle, West eld State College,cdoyle@wsc.ma.edu

\section{Native American heritage in the nation's capital}

The 2007 Anthropology and Sociology Section (ANSS) program, "Native American Heritage in the Nation's Capital: Representation, Repatriation and Resilience," featured an interdisciplinary panel of four scholars.

Candace Greene (ethnologist at the National Museum of Natural History) is a specialist in Plains Indian pictorial art and senior editor of The Year the Stars Fell: Lakota Winter Counts. Green explained that winter counts are calendrical documents, often kept on buffalo robes, where each year is denoted by a pictogram. The Year the Stars Fell refers to the Leonid meteor storm of November 1833, an event depicted on all known Lakota winter counts. Green worked with Lakota people to curate a Web exhibit (wintercounts.si.edu) that was honored with a World Summit Award in 2005.

Emil Her Many Horses (associate curator at the National Museum of the American Indian) is a member of the Oglala Lakota nation. He was lead curator for the inaugural permanent exhibition "Our Universes: Traditional Knowledge Shapes Our World," which focuses on indigenous cosmologies-worldviews and philosophies related to the creation and the order of the universe. During his presentation about the development of "Our Universes," Her Many Horses highlighted his collabo- 
rations with the Quechua of Peru and the Yup'ik people of Alaska.

Dorothy Lippert (archaeologist at the National Museum of Natural History) discussed the contradictions and complexities arising from her multiple identities as a Choctaw, an archaeologist, and a repatriation case officer. She discussed how the 1990 Native American Graves Protection and Repatriation Act (NAGPRA) is ameliorating long-standing tensions between archaeologists, museums, and native peoples.

Suzan Shown Harjo (Cheyenne and Hodulgee Muscogee) is president and executive director of the Morning Star Institute. She is a poet, writer, lecturer, curator, and policy advocate, who has helped native peoples recover more than 1 million acres of land and numerous sacred places. Harjo gave a moving personal account of her role in the passage of important federal legislation, including NAGPRA and the National Museum of the American Indian Act.-Terry Epperson, College of New Jersey, epperson@tcnj.edu

\section{Federal documents in African American genealogical and historical research}

ACRL's African American Studies Librarians Section (AFAS) presented a two-hour workshop to help librarians to bridge the information gap about the legacy of Africans in America. Reginald Washington (National Archives and Records Administration) led the highly successful workshop and provided the standing-room-only crowd with loads of detailed information and advice for uncovering African American genealogy in government resources.

Many of the standard sources for the history and genealogy of European people in the United States cannot be used to chronicle the history of African Americans. Washington explained that those of African descent were considered three-fifths of a human by the federal government and were listed with livestock and other chattel, so they would not be listed in genealogy sections of county histories or the census until some time later.
For example, federal census records for many years only listed the few free persons of African descent and not the many who were enslaved.

Washington also informed participants that the Record of the Commissioners of Claims (Southern Claims Office, M87) is a treasuretrove of information about the lives of 19thcentury African Americans. This collection includes many long narratives of former slaves; each claimant was asked 80 questions about his or her lives, providing information that is not available anywhere else.

The AFAS two-hour workshop organized by cochairs, Akilah Nosakhere and Vivian Fisher, proved extremely popular among conference attendees. Fisher presented Reginald Washington with a Crystal Book Award in recognition of his advocacy for the preservation of federal documents chronicling the experience of Africans and African Americans in the United States. Washington gave congressional testimony in support of the Freedman's Bureau Preservation Act of 2000 that authorized $\$ 3$ million for the preservation of more than 1,000 linear feet of field office records at the Freedman's Bureau.

Participants of the workshop received an extensive packet of handouts that was put together by AFAS volunteers. Some of Washington's work is available on the Web site he maintains at the National Archives and Records Administration, see www.archives. gov/research/alic/reference/black-history -topical.html.

Pictures of the AFAS program are available on Flickr at www.flickr.com/photos /12682543@N00/sets/72157600530982134/. -Isabel Espinal, University of MassachusettsAmberst, iespinal@library.umass.edu

\section{Empowering data: Persuasion through presentation}

Three lively and informative talks were given at the ACRL Education and Behavioral Sciences Section (EBSS) program "Empowering Data: Persuasion Through Presentation." The featured speakers were Robert Molyneux (SIRSI/DYNIX), Steve Hiller (University of 
Washington), and Maribeth Manoff (University of Tennessee.)

Molyneux, the first speaker, provided an overview of library aggregate data collected by organizations, e.g., ARL and ACRL, and agencies such as NCES. He noted we use data for funding justification and decision support, not for research ascertaining cause. Although this data is primarily collected annually, the compilers do not generally create longitudinal files, and this severely limits our ability to study trends. Documentation and data selection can also be a problem. Data collected by others, such as NCES, is well documented, but doesn't necessarily answer librarians' questions. Conversely, data collected to answer our questions when available is often poorly documented. This latter weakness makes compilation even more difficult.

These structural weaknesses in the data, however, will be addressed in the near future with the release of the Academic Libraries Statistical Longitudinal File (and its derivative products) by the National Commission on Libraries and Information Science. Molyneux concluded by encouraging us to consider exploring this data more fully and to "jump in ...there are many questions that need answers."

The second speaker, Steven Hiller, focused on how we can make data meaningful and actionable, using a detailed assessment project at the University of Washington as a case study.

Hiller suggests we must first select the appropriate method(s) and/or data sets, and then compile, summarize, and analyze the results in ways that increase understanding. For example, using descriptive statistics, one can highlight themes or patterns. Comparisons (chronological, within and between groups, institutions, and norms) can also provide context. The findings presented should be key results that are usable or actionable; often the most effective way to provide these findings is graphically.

The final speaker, Maribeth Manoff, used a more narrow focus on e-resource usage to illustrate the iterative process of using data. She first discussed the MaxData Project, funded by IMLS, which seeks to evaluate and compare methods of usage of data collection and to analyze and develop a cost/benefit model to help the selection of methods for electronic resource usage assessments. Manoff then turned specifically to the University of Tennessee Libraries usage data, and, as Hiller previously discussed, she emphasized the importance of evaluating what data is available, identifying the questions we are trying to answer with the data, and analyzing and reviewing what makes the data useful and may lead to new questions that start the process over again.

Presentation slides from this program are available at www.ala.org/ebss/empoweringdata. -Karen A. Hartman, Rutgers University, khartman@rci.rutgers.edu

\section{Rare books and special collections in public libraries}

Rare and antiquarian collections are most often associated with academic institutions, historical societies, and museums; however, special collections are also found right around the corner within your local public library. ACRL's Rare Books and Manuscript Section (RBMS) partnered with the Public Library Association (PLA) to highlight these significant collections and the libraries that house them, during the program entitled "Rare Books and Special Collections in Public Libraries: Collections and Locations, Old and New." A sampling of three public libraries-each varying in size, scope, and mission-were represented.

Elaine Barone (manager of the humanities division of the Buffalo Public Library [BPL]), detailed examples of modern fine printingKelmscott Press publications, Shakespeare's first folio, incunabula, the Federalist Papers, and Mark Twain's manuscripts-as some of the 40,000 titles found in their catalog. These collections reflect the glory days of BPL; as it was one of the country's 11 largest libraries up until the 1950s. Discussing financial cutbacks, reduced staffing and hours, and the difficulty of making collection development decisions 
with fewer funds, Barone spoke to the role and impact of community pride in maintaining these treasures.

During the formative years of the collections, the 1920s-1930s, the people of Buffalo contributed their own hard earned funds to ensure that the rare materials of the science collection would be fully represented in their library. According to Barone, a sense of ownership and pride in the materials has developed because of key library initiatives. She mentioned the use of exhibitions, publicity, advocacy within the community, and the development of a treasure's presentation, as some successful methods for growing community support, involvement, and investment.

Gladys Mahoney (rare book librarian at the Phoenix Public Library) provided background and details of the Arizona Room's local history collection, the Rare Book Room's community book art collection, Washington Press, and the Alfred Knight Collection of Rare Books. She stated that three components sustain and enhance collections: public access, marketing and programming, and support and advocacy. Phoenix Public Library (PPL) creatively implemented activities and policies surrounding these three components to build its patron base, increase support, and maintain funding levels: a relationship with the Arizona University Book Arts Program was forged in 1981, access to the collections was increased via the online catalog, a regular presentation schedule was instituted for all ages, and the printing press was opened to the public under Mahoney's guidance and skill. Patronage is PPL's focus, which keeps the staff ever mindful of their mission no matter how numerous the challenges.

Francine Henderson (head of the Auburn Avenue Research Library on African-American Culture and History) described her current role as the culmination of a lifelong, fantastic journey and the melding of experiences. As the leader of the nation's second largest archives specializing in the history of African Americans, Henderson asserted that libraries need to develop a public awareness of col- lecting and maintaining historical information and materials; assess potential collections, donors, and topics of significance within the community; provide information that will help to demystify the process of collection building; and to promote advocacy for better preservation and access of African American culture and history at research institutions. Henderson also spoke to the public distrust of majority institutions. In summation, she said, "You don't have to die in order to donate your papers, give them now, and go to your own party!"

The program ended with a question-andanswer session. One member of the audience thanked the speakers heartily, as they offered practical advice. Another attendee raised the issue of a local donor base and whether it competes with other regional, cultural institutions. According to Henderson, a community has many needs, and your institution is fulfilling a specific need, not competing.-Eileen M. Heeran, Cornell University,emb57@cornell.edu

\section{The European Union today}

Significantly for libraries, the European Union (EU) has an ever-stronger impact in the arenas of global publishing, scholarly communication, and information services even beyond contemporary Europe. Members of three ACRL sections gathered to hear three different perspectives on the enlarged EU and on European identity issues. Planned by the Western European Studies Section (WESS), the program was cosponsored by the ACRL Law and Political Science Section (LPSS) and the Slavic and East European Studies Section (SEES).

John Bruton (ambassador of EU to the United States and former prime minister of Ireland) was one of three distinguished speakers. Bruton addressed several transatlantic issues, including environmental policy; attendees praised his insight and dry humor. His participation was a welcome affirmation for librarians, as it coincided with news of the transfer of the print library of EU's Washington Delegation to the University of Pittsburgh, where it will be digitized. That library and its 
staff have been a greatly appreciated resource for EU research and general inquiries for more than two decades.

European identity and the social construction of political authority within the EU are research areas for Georgetown University Professor Kathleen McNamara. Her history of the development of European nation states and the EU provided essential context for the substantive discussion following these presentations, which she moderated.

Arend Kuester (director for Europe of Publishers Communications Group (PCG), Inc.) offered a rich presentation, providing both the facts and the flavor of the Eastern European information infrastructure and some EU publishing issues. Photographs from his travels to all major libraries in all Eastern European EU members and candidate countries enlivened his presentation.

Attendees praised the quality and credentials of the speakers, their varied and engaging presentation styles, and the breadth of information provided about EU history and some of the contemporary identity issues. We look forward to more WESS forums and discussions on this area.

Additional information about this program can be found on the WESS Web site at wess. lib.byu.edu. Sarah How, Cornell University, seb4@cornell.edu

\section{The compleat leader}

The question posed in the University Libraries Section (ULS) program "Leadership or Management: Which is It?" has an admittedly obvious answer: both; yet the implications of this response are far more complex than this single-syllable response would suggest. The program title served as the starting point for an expansive discussion of the skills employed by the individuals who stand at the helm of our organizations, and of the need for a conscious awareness of when we draw from leadership skills and when we draw from management skills for the betterment of our libraries.

The program featured a panel of individuals at different points in their careers: Julie
Todaro (dean of library services at Austin Community College and ACRL presidentelect), representing those more established in librarianship; Karen Williams (associate university librarian for academic programs at the University of Minnesota Library), speaking as a mid-career librarian; and Adam Benitez (recent graduate of the University of California-Los Angeles' MLIS program), as a brand new librarian with many years of paraprofessional experience. Moderating the panel was Shelley Phipps (assistant dean for team and organizational development at the University of Arizona Libraries). A panel with such diversity in the participants' career stages offered insight into the ways leadership and management are viewed from these different points.

Todaro set the stage by describing the "versus" theory of leadership vs. management, in which the former is considered an art and the latter a science, the former about people and the latter about resources. Historically these have been considered separate schools of thought about how to run an organization, but in recent years there is more reflection on ways to blend the two in scholarship and training.

Karen Williams responded by emphasizing the importance of "making every librarian a leader," as per Walter Minkel's 2002 article in School Library Journal. Positional leaders need to take advantage of both leadership and management skills, Williams agreed, but she added that this is not enough, and the same skills are important to those in all library positions across the board. She asserted that leadership can be learned; we just need the training, education, practice, and reflection to make those skills our own. And, above all, leaders must be intentional in their employment of leadership and management skills in their work.

In contrast to Todaro's and Williams' polished presentations, Adam Benitez took the stage with endearing, acknowledged nervousness. He described being surprised when he was asked to join the panel. "I was just doing my job," he said, adding that he 
did not consider himself a leader. In his view, mentors are the key to training new leaders, and he cited encouragement he received from colleagues as a motivating factor that helped him get through library school. The most important role of a leader, he suggested, is to create new leaders by helping others see themselves that way. In short, new leaders are created by those around them, through mentoring and shared enthusiasm.

To round out the session, Julie Todaro returned with an effort to weave together the topical threads provided by Williams and Benitez. She provided a handout (available at www.acrl.org/ala/acrl/aboutacrl /acrlsections/universitylib/ULSMeetings.htm) that elaborates on the differences between leadership and management and offers some explanation about the importance of each, as well as ideas for training future leaders and managers. Reviewing the handout, Todaro detailed ways in which current leaders can be intentional in providing for succession planning by deliberately hiring individuals who complement their own skills and weaknesses and have the potential to step up to the next level. Further, she described a combined leadership/management approach in which the managers take the facts and add the human element as leaders, with the result being a more complete and effective perspective.

As an example, Todaro recounted a memo she wrote to tell her staff about construction that would take place in the library. As a manager, she was concerned with conveying the dates, locations, and contingencies of the construction (such as noise, closed areas, etc.). However, as a leader she made sure to offer those facts in a greater context; providing a sense of purpose for the project, an offer for those affected by noise to work alternative hours, and thanking staff for their flexibility. As she described this experience, Todaro explained how leaders should consciously draw from leadership and management skills by reviewing a list (such as the one in her handout) and deciding which of those skills are appropriate and when.

Overall, the ULS program was an engag- ing foray into the question of how to create stronger leaders through a conscious blend of leadership and management skills, with a side trip into the question of how to recruit, train, and advance future leaders in a profession that is sure to need them-and soon. The session, which took place in a sizeable auditorium, was well attended and (to gauge from the number of seats still occupied by the end of the session) clearly well received. The session was followed by a social hour with representatives from nine national library leadership programs, as an opportunity for attendees to network and learn about new leadership opportunities._Kim Leeder, Boise State University, kimleeder@boisestate.edu

\section{Once upon a Furl in a podcast long ago}

This year's annual conference program of the ACRL's Women Studies Section (WSS), entitled "Once Upon a Furl in a Podcast Long Ago: Using New Technologies to Support Library Instruction," was standing-room only and offered up a well-rounded panel of guests who have firsthand experience with implementing new technologies in the classroom and beyond. The panelists were, respectively, Joan K. Lippincott (Coalition for Networked Information), Kathleen Burnett (Florida State University's Information Studies Program), Kathryn Shaughnessy (St. John's University), and Heather Tompkins (Carleton College).

Although this program emphasized library instruction as its subject, it became clear that the focus was primarily on the programmatic uses of new technologies; the last acknowledging that at the moment in which teaching happens, that particular moment has been filtered through administrative acceptance, faculty and student input, engagement with new material, and programmatic policies requiring and providing opportunities for change. It is becoming more acceptable in academic libraries to use technology in an experimental fashion. Yet, just as in any scientific lab, these experiments occur in an environment of controlled sustainability. Projects conducted before to the Web, social 
or otherwise, have left terrific paper tiger trails but much to be desired in terms of flexibility. In comparison, the experiments shared by our panelists seem to have regenerative properties, able to adapt to shifting administrative landscapes and student preferences. As panelist Kathryn Shaughnessy stated, "Library 2.0 is always in beta."

True to its word, "Once Upon a Furl" highlighted many creative new technologies and projects. Many of these technologies have familiar names, such as Skype, Blogger, RSS, PennTags, Captivate, RefWorks, and del.icio. us. However, the overarching theme of the program was not to simply showcase technology-rich projects, but to emphasize the use of technology as a vehicle for communication, collaboration, and curricular enrichment. Joan K. Lippincott shared examples of how some institutions are handling multimedia on their campuses. Projects such as TeamSpot at Stanford and Georgia Tech's Practice Presentation Room have led the way by providing students unfettered opportunities to become savvy information producers, something they are already working on in their personal lives. These collaborative workspaces empower students to make an important transition from, according to Lippincott, the "recreational use of technology to academic use of technology."

\section{Communication}

Increasingly, it has become a priority for academic librarians to create multi-channel avenues of communication with both students and faculty. In an effort to provide resources and services to a generation that, as Lippincott states, "never were tethered to communication in a place," librarians have built new outposts of communication that extend the building, the classroom, and our definition of ourselves. By building social networks, using technologies that students have already embraced, librarians can ensure more timely delivery of resources and services. Additionally, these technologies provide the flexibility to repackage and restructure resources and services in order to meet, as they say in the corporate world, client specification. As panelist Heather Tompkins aptly states, these new technologies are ideally suited "social Web applications as a tool for organizing research." Tompkins also points out that meeting students where they are comfortable is an opportunity to teach concepts about academic research in a non-threatening environ. In addition, by sharing resources and project goals with other academic departments, librarians can more closely examine their success in teaching many of the core skills needed to transform information literacy. According to Lippincott, these core skills, as extrapolated from Henry Jenkins' work Confronting the Challenges of Participatory Culture, include the ability to multitask, simulate, and meaningfully appropriate.

\section{Collaboration}

Selective and successful appropriation, or sampling, of different media sources means that students and faculty alike are more likely to, as Kathleen Burnett suggests, "bring other voices and faces into the discussion." And, by expanding our concept of acceptable forms of scholarly communication, we create new opportunities for interdisciplinary collaboration. Collaboration flattens the learning environment, coaxing it into one more akin to mutual aid. Kathryn Shaughnessy points to this in her discussion of social justice concerns for instruction, where she emphasizes learning from students, in "recognition of experience/expertise in their own area." The benefits of collaboration and teamwork were threaded through each panelist's presentation. As Burnett emphasized in her discussion of digital natives, this is especially true of library and information science students, who come to the profession from diverse backgrounds and have much to gain from an increase in "peer-to peer (collaborative) learning" strategies.

\section{Curricular enrichment}

Burnett and others also note that new technologies have made a variety of experiential learning activities possible, such as gaming 
and simulation. These types of learning strategies match the learning preferences of digital natives, or millenials, which include a desire for active engagement and constructive versus theoretical learning experiences. They want to do rather than discuss, and they want the unadulterated version of what they are learning. In short, new technologies give students and faculty more flexibility in the types of material being presented, how that material is presented, and the ways in which it is delivered. This means a change in expectations, not only as to what constitutes scholarly communication, but in how faculty and students interact.

As we move forward with these and other new technologies, it seems important to recognize that this is ever-shifting terrain. What seemed anathema to learning 20 years ago (studying via podcast while driving?) or structurally impossible 10 years ago (transnational synchronous distance learning?) is now part of our learning culture. The best piece of all of this is that through technology, academic librarians have developed into a new breed of professor, one capable of providing guidance as to the hidden pedagogical potential of technology and teasing out the ever soughtafter student wow factor.-Jennifer Nace, Pennsylvania State-Worthington Scracton, jxn19@psu.edu

\section{Librarians and fundraisers: More in common than you might suppose}

The ACRL Ethics Committee sponsored "Ethics and Fundraising: Challenges and Opportunities," a presentation featuring two experienced library fundraisers who provided the audience with an informative and thought-provoking session that stressed the ethical foundation of fundraising activity.

Bill Myers (former director of library development and current director of assessment and outreach within the Office for Information Services at the University of Kansas) set the stage for the presentation by asking audience members to consider the Ethical Dilemma Test, from the National Institute of Ethics. which poses questions like "What would
I do if I were being videotaped?" and "Would I do it if my family was standing beside me?" Myers also asked the audience to think about three words that describe effective librarians and three words that describe effective fundraisers. The lists contained several words in common, such as honest, integrity, and bardworking. This exercise reinforced Myer's conclusion that the two professions have a great deal in common.

One major distinction between the two is in terms of practice: people ask librarians for something, while fundraisers ask people for something. The integrity of both transactions depends upon the integrity of the individuals conducting them and adherence to a well articulated set of professional principles. Librarians have the Library Bills of Rights and the ALA Code of Ethics; fundraisers have the Donor's Bill of Rights and the Association of Fundraising Professionals Code of Ethical Principles.

Dwain Teague (director of development for the University of Central Florida Libraries) identified three challenges to fundraisers working in the library environment: identifying potential donors, educating constituents as to how they can show their support, and overcoming the idea that a library is simply a building that houses books. Teague stressed that education and communication are key factors in establishing and maintaining good relationships with donors and prospective donors. The audience enjoyed his "tales from the trenches" as he highlighted potentially tricky situations involving gifts of books and nonbook material that were resolved effectively by the library being forthright about its priorities while respecting the intentions of the donor for the gift.

Both speakers agreed that it is essential for libraries to have a clearly defined set of polices and procedures in place. Library staff and donors alike should be familiar with these documents. Myers suggested including ethics as part of a formal program of orientation or staff development.

The program is best summed up in the words of Douglas E. White, a writer who 
has made significant contributions to the literature of professional fundraising: "The trick is not only to want to do the right thing, but to have done the work to understand and defend what the right thing is."-Lori Phillips, University of Wyoming Libraries, lphil@uwyo.edu

\section{Conquer your peer fear}

ACRL's Distance Learning Section (DLS) presented a program about the peer-review process, "Conquer Your Peer Fear: A Mock Peer-Review Workshop." The program was aimed at new authors who have not been published in peer-reviewed journals. The program began with a brief award ceremony.

Sandra Hawes (DLS conference planning chair) introduced the participants. Connie Hildebrand (DLS award chair) presented the 2007 ACRL DLS Haworth Press Distance Learning Librarian Conference Sponsorship Award to Anne Marie Casey (associate dean of libraries at Central Michigan University). This award includes a plaque and $\$ 1,200$ to assist with the expenses of attending ALA's Annual Conference.

Alan Karass (music librarian at College of the Holy Cross and coeditor of Music Reference Services Quarterly) and Stephen Dew (past editor of Journal of Library \& Information Services in Distance Learning) offered advice about preparing and submitting articles for publication in peer-reviewed journals. Both presenters provided handouts with peer-review publishing tips. The DLS Research Committee provided a two-sided handout with detailed information (in table format) about presentation opportunities at forthcoming conferences of interest to distance learning librarians.

Karass showed excerpts from drafts of papers that had been solicited prior to the conference. With these excerpts, he demonstrated common problems of first-time authors and suggested solutions. He also provided general advice for writers, such as staying focused on the topic, using a formal writing style, considering time sensitivity when deciding where to submit an article, and submitting the article with an abstract and author-provided keywords. Dew suggested that hesitant writers start with something small, such as a newsletter article or book review. When writing an article for publication, Dew advised authors to follow carefully the journal's instructions for authors, organize the paper in a logical manner, be consistent with acronyms and job titles, avoid first-person writing except for an editorial or opinion piece, and welcome criticism and suggestions from peers.

Audience members actively participated in the question-and-answer session that followed the editors' presentations. DLS collaborated with the ACRL's Education and Behavioral Sciences Section (EBSS) by mutually promoting their programs.-Liz Richardson, Edinboro University of Pennsylvania, erichardson@edinboro.edu

\section{Issues and trends in digital repositories of nontextual information}

Catherine Soehner (University of Michigan, Science and Technology Section [STS] chair) welcomed more than 200 participants to the session and presented the Oberlin Award for Bibliography in the Agricultural Sciences to Louise Letnes, Patricia Rodkewich, and Julie Kelly (all of the University of Minnesota) for their database AgEcon Search agecon.lib.umn.edu/.

Information on the Oberly Award is found at www.ala.org/ala/acrl/acrlawards /oberlyaward.cfm.

Program committee member Katherine O'Clair (Arizona State University) introduced the speakers: Thomas Dowling (OhioLINK), speaking on "Building OhioLINK's Digital Resource Commons: A MultiMedia, Multi-Institution (And Sometimes Even Open Access) Research Repository"; D. Scott Brandt (Purdue University), whose talk was titled "Data, Research, Metadata, Metaresearch"; and H. Frank Cervone (Northwestern University), who focused on "The University Library and its Role in Facilitating Campus-wide Streaming Media."

Thomas Dowling (assistant director of library systems, client/server applications at OhioLINK), began with a brief history and 
timeline of development of the OhioLINK Digital Media Center (dmc.ohiolink.edu/). Its first collection became accessible in 1999 and will be just one component of the planned Digital Resource Commons (DRC), a statewide institutional repository. The vision for DRC includes:

- statewide institutional repository: research portfolios such as preprints, postprints or working papers,

- Web-mediated peer review electronic journals: supporting open access self-archiving and publishing,

- electronic theses and dissertations: Webmediated submission, tracking, acceptance, and publication of student works,

- learning object repository: connected to a campus' Collaborative Learning Environment (CLE) for storage and retrieval of course content, and

- online exhibition system: digital library platform for libraries, archives, and special collections and more than 10,000 electronic dissertations from 17 institutions in Ohio.

Dowling spoke candidly of the difficulties encountered due to the complexity of working with 85 different institutions statewide, the "vertical diversification" of the content, and the need to move seamlessly from a single institution's repository to the statewide repository. Initial plans to work with Fedora are being re-evaluated; installing "several silos" of content using DSpace and building connections between those is under consideration. The challenges of integrating perhaps 100 repositories around the state (including branch campuses), compatible with Open Archives Initiative Protocol for Metadata Harvesting, are not insignificant. Current progress toward DRC can be followed at drc-dev.ohiolink.edu/

Scott Brandt (associate dean for research, Purdue University) emphasized the role of academic librarians in the "research stream"-not simply interacting with published data, but as partners who capture data and unpublished materials for a data repository. Brandt gave as an example the Journal of Molecular Biology. This scientific journal requires deposit of data to support a manuscript, and librarians are well qualified to collaborate with scientists so these data are captured, described, and made accessible to an appropriate audience. Purdue is exploring how to work with more faculty, respond to researchers who desire a broader audience, and use automated methods for capturing and processing data.

Brandt offered this practical advice to librarians: ask researchers "What are you working on? How do you share data? Do you need to share data? Can we work with you to describe and house data?" These questions will facilitate problem solving, not simply building a repository. Librarians can help with ontologies, hierarchical structures, and interactive thesauri, and are well positioned to balance service with research. Building strong relationships with researchers is key to creating repositories that serve the needs of researchers and users.

Frank Cervone (assistant university librarian for technology, Northwestern University) described an ambitious project to bring streaming media to 18,000 FTE students on a widely distributed network. At the outset of the project, the video infrastructure badly needed an overhaul, and technology-enabled classrooms were just beginning to be installed. The new system requirements featured a standard, integrated method for ingesting, storing, and accessing digital objects and the ability to streamline workflow of processing digital media (including metadata creation).

Cervone provided technical details on streaming media protocols considered at Northwestern during the project planning phase, including stateful protocols vs. nonstateful protocols (the latter is better for streaming video, with less overhead in error correction, and minimizes dropped data), and variable protocols (such as MMS, UDP, TCP, HTTP), as well as considerations related to unicast or multicast. An academic environment often requires a unicast (for example, one student watching a lecture from the previous day), but many unicasts 
simultaneously can overwhelm a system in a manner unlike the multicast protocol. The Web site AllStreamingMedia.com maintains a helpful FAQ at all-streaming-media.com /articles/Streaming-Media-Intro_Streaming -protocols.htm.

VideoFurnace is installed at Northwestern, offering secure video distribution compatible with MPEG standards. It is not a repository system, but it is ideal for streaming and allows conversion of old analog video to digital for archiving. Fedora is used at Northwestern for the repository currently under construction. Cervone also described the role of VideoFurnace in the production of NUTV, Northwestern television at www.it.northwestern.edu/tv /index.html.

Questions for the three speakers ranged from the feasibility of the Open Archives Initiative (OAI) for metadata harvesting to the long-term cost (in staff and technology) for data curation and the observed allegiance of researchers to disciplinary archives vs. institutional archives. Regarding OAI, the speakers emphasized that metadata cannot be limited to simple Dublin core, ignoring how the data will "look out in the wide world" and specifically to OAI harvester. Cost issues may be addressed to some extent by partnering with other institutions to realize economy of scale within a consortia or regional repository. With pressure growing for open access to government-funded research, academic communities will have to be prepared to allocate funds for data preservation, with links to published research.

Finally, managers of repositories need "fluid policies" so that researchers can readily deposit materials in the repository that make sense for them, and for their colleagues and students. Dictating policy across disciplines and a wide range of users will not guarantee compliance. Success will be measured by how well faculty, library, and information technology professionals collaborate to make the connections functional, and the systems intuitive and accessible to the widest community possible.

Program information is available at www.ala.org/ala/acrl/aboutacrl/acrlsections /sciencetech/stsconferences/program07. cfm-Alison Ricker, Oberlin College Science CenterLibrary, alison.ricker@oberlin.edu

\section{Shakespeare in libraries}

The Literatures in English Section (LES) and the Theater Library Association cosponsored a well-attended program entitled "Shakespeare in Libraries: On Stage, Online, Off the Shelves."

Georgianna Ziegler (Folger Shakespeare Library) began by describing the Folger's history and collections. The library serves a broad community beyond the academic world, and its e-mail reference service is used by theater professionals, book dealers, librarians, and students of all ages from all over the world. The Folger is putting more of its material online to better serve this global constituency.

Caleen Sinnette Jennings (American University) emphasized the importance of faculty and librarians working together as coeducators, drawing from her own positive experience working with a reference librarian in support of a theater seminar she taught. She urged librarians to reach out to faculty members and to promote "the cultural and ethnic diversity of literature in general and Shakespeare in particular."

James Harner (Texas A \& M University) lamented the poor quality of many online Shakespeare resources, claiming that "the Bard is not well served by the brave new electronic world." He advocated for the creation of an electronic Shakespeare clearinghouse, organized and maintained by librarians, which would be rigorously selective and evaluative, serve both $\mathrm{K}-12$ students and advanced researchers, and include "the scholarly as well as the fun stuff."

Carole Levin (University of NebraskaLincoln) described her involvement with the "Elizabeth I: Ruler and Legend" exhibit, for which she served as senior historical consultant. Originally on display at the Newberry Library, the exhibit later traveled to 40 public and academic libraries across the country. Levin described the creative public program- 
ming that the hosting libraries developed to supplement the exhibit and engage the public.

The discussion after the presentations touched on hot topics in current Shakespeare scholarship, including cognitive theory, globalization, ecocriticism, and performancebased approaches to teaching. All of the panelists stressed the scholarly importance of engagement with physical books and manuscripts, despite the increasing availability of digital surrogates, and the important role of libraries in fostering scholarly community.-Chris Ruotolo, University of Virginia, ruotolo@virginia.edu

\section{Visual literacy meets information literacy}

The Arts Section and Instruction Section (IS) cosponsored "Eye to I: Visual Literacy Meets Information Literacy" to a capacity crowd of more than 400 attendees. The afternoon began with the presentation of the IS awards.

The Miriam Dudley Instruction Librarian Award (sponsored by Elsevier) went to Debra L. Gilchrist (dean of library and media services of the Pierce College District) for her significant contributions in the area of assessment of information literacy.

The University of North Carolina-Chapel Hill Library's Instructional Services Department was awarded the IS Innovation Award (sponsored by Lexis-Nexis) for its "Community Workshop Series." Rounding out the awards, James K. Elmborg (University of Iowa) and Sheril Hook (University of Toronto-Mississauga) were given the Ilene F. Rockman Instruction Publication of the Year Award (sponsored by Emerald Group Publishing) for their collaboration on Centers for Learning: Writing Centers and Libraries in Collaboration, Publications in Librarianship $\# 58$.

The dynamic program that followed focused on forging connections between visual and information literacy, and included looking at legal aspects, access issues, and teaching strategies in an environment where images and words are increasingly interwo- ven to make meaning. This point was powerfully illustrated at the program's opening when images of historical events, including John F. Kennedy's assassination and the levee breaches in New Orleans after Hurricane Katrina, were juxtaposed with headlines of those same events.

Three dynamic speakers then explored the topic in-depth. Danuta Nitecki (associate university librarian of Yale University) set the stage by discussing how images are an increasingly important way people communicate, and visual literacy consisted, at its most basic of an understanding of how this communication worked.

Loanne Snavely (head of instructional programs at Pennsylvania State University Libraries) then explored the complexity of ownership issues related to images, illustrating her point by presenting images of artwork and photographs to the audience whose credits and copyrights were anything but obvious.

Introducing yet another layer of complexity to working with visual information, Cindy Cunningham (director of media metadata and cataloging at Corbis Corporation) presented a series of images and asked the audience to consider what keywords they would use to catalog the images. The audience favored simple descriptors over more complex emotional or conceptual ideas, but the catalogers at Corbis included both, and Cunningham explained why it was important to accommodate users searching in a visual mode.

Nitecki then returned to the podium to present an approach to creating teaching objectives for visual and information literacy. She offered an assessment rubric (developed with colleagues at Yale) that measured the level of visual literacy a learner had achieved. Snavely went on to present specific techniques for teaching visual and information literacy during instruction sessions. Cunningham closed by emphasizing the coexistence of words and images in our information-rich world and the need for an

(continues on page 517) 
as possible. (We added two units midway through the conversation.)

3. Don't get bogged down about what is not possible.

4. Encourage free association outside of the meeting times by setting up a virtual place where conversation continues or by setting up a fast-response e-mail network.

5. Realize that while collaboration is challenging, it is needed and people all the way up to the chancellor will be happy with the results!

\section{Notes}

1. Service providers: The library, the Center for Teaching and Learning (CTL), the bookstore, faculty themselves (do-it-yourself Web sites), webCentral (the student portal), University Technology Services (UTS), multimedia services within UTS.

Services provided: Checking copyright and paying permission fees; and identifying, obtaining, delivering, maintaining, reformatting (including digitizing), creating, and supporting course-related materials.

Venues for distribution of course-related content to students: DU VAGA (a visual material viewer created and managed by CTL), Blackboard, Portfolio (student and faculty assessment and document-posting environment created by CTL), course packs and textbooks provided by the bookstore, faculty personal Web pages, inclass handouts, the library e-reserve software, webCentral, and the library circulation desk.

Products available electronically: library tutorials, reference guides, journal articles, assessment materials (forms, tests, bluebooks), book chapters, calendars, communication forums (e-mail, discussion board, chat), electronic books, forms, images, video recordings, presentations, PowerPoint, lecture notes, sound recordings, student work, syllabi, Web links.

Products available physically: journal articles, assessment materials (forms, tests, bluebooks), book chapters, books, forms, images, presentations, PowerPoint, lecture notes, student work, syllabi, video recordings, Web links.
2. Visit the One-Stop Course Materials Guide at ctl.du.edu/resources/course.cfm.

3. DU VAGA is a courseware tool for organizing and presenting high-quality images and videos to course participants. Instructors have access to more than 20,000 art and world history images and more than 200 library reserve videos.

4. The video search guide can be found at library.du.edu/FindIt/ResearchGuides /rg_main.cfm?rg_id=187. „2

( ACRL in Washington, D.C. continued from page 497)

increased focus on how we organize and teach visual information.

A virtual poster session focusing on "practical applications of the intersection of visual and information literacy" was developed in conjunction with the program, and is available at eye2i.wordpress.com/.-Kevin Unrath, Western Carolina University,Unratb@email. wcu.edu $\rightleftharpoons$

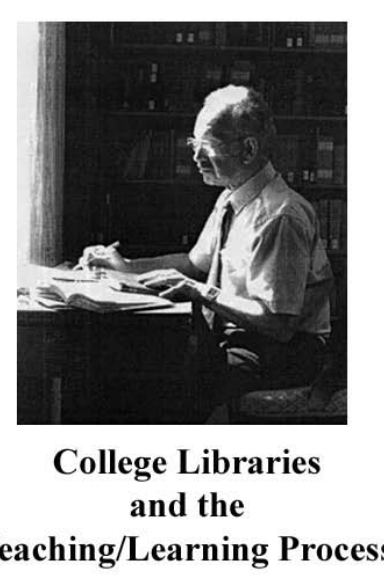

Selections from the Writings of Evan Ira Farber 1974-2004

Ordering Information: ISBN: 9781879117181

Earlham College Bookstore 801 National Road West Richmond, IN 47374 765-983-1310 www.earlhambookstore.com

Price: $\$ 29.00+\$ 6.95$ (shipping) 